\title{
An analysis of Japan's English as medium of instruction initiatives within higher education: the gap between meso-level policy and micro-level practice
}

\author{
Ikuya Aizawa ${ }^{1}$ (D) Heath Rose ${ }^{1}$ (D)
}

Published online: 3 November 2018

(C) The Author(s) 2018

\begin{abstract}
In 2014, Japan's Ministry of Education (MEXT) announced the Top Global University Project (TGUP), a large-investment initiative to internationalise higher education that implicitly signalled increased emphasis on English-medium instruction (EMI) at Japanese universities. Despite substantial funding behind the initiative, little research has evaluated the implications for language planning, including contextualised implementation challenges. This study aims to investigate how the policy is being enacted into practice at a university in Japan at two different policy levels: the meso (institutional) and micro (classroom) level. The study contrasts one university's TGUP meso-level policy documentation with data from semistructured interviews with students and teachers to illuminate micro-level challenges. Data were coded according to emergent themes via qualitative text analysis, following similar processes to research into TGUP policy. The findings suggest that the meso-level policy goals of the university do not trickle down to micro-level practice as envisioned, revealing underlying challenges arising from policy diffusion. In comparing our results with data from other TGUP university studies, we conclude that micro-level linguistic challenges for teachers and students has relevance for other universities where English-taught programmes are being expanded via national and university-level policies.
\end{abstract}

Keywords Japan · EMI · Internationalisation · Globalisation · English language

\section{Introduction}

One of the most prominent higher-education (HE) trends in the twenty-first century has been the drastic expansion of English-taught programmes in countries where English is not the

Heath Rose

heath.rose@education.ox.ac.uk

Ikuya Aizawa

Ikuya.aizawa@education.ox.ac.uk

1 Department of Education, The University of Oxford, 15 Norham Gardens, Oxford OX2 6PY, UK 
native language (Wächter and Maiworm 2014). This trend is a consequence of the increasing globalisation of HE (Healey 2008) coupled with the emergent status of English as the world's academic lingua franca (Galloway and Rose 2015). Japan is no exception to this situation, facing a growing push to cultivate local students with calibre to participate in the international workforce. The need to achieve globalisation has been pushed by Japan's Ministry of Education, Culture, Sports, Science and Technology (MEXT), which has invested heavily into HE internationalisation policies. As a preliminary initiative, in 2009, MEXT launched the heavily funded Global 30 Project, which aimed to increase the number of foreign students and internationalise Japanese HE with an explicit emphasis on an increase in English-medium instruction (EMI).

Similarly, in 2014, MEXT announced the more recent initiative of the Top Global University Project (TGUP) with the aim "to enhance the international compatibility and competitiveness of higher education in Japan" (MEXT 2014). Although EMI is gaining momentum in Japan and the TGUP initiative is well-funded, to date, little research has been conducted to examine the implications of this initiative for language-related planning in Japanese participant universities (Bradford and Brown 2018; Rose and McKinley 2018). This study, therefore, aims to fill this gap by exploring how the TGUP is interpreted and implemented by one participant university, analysing its language-related strategic plans in detail. It also evaluates how its students and teachers have responded to the push for EMI, under the most recent policy. By understanding how this initiative is being comprehended by different parties at the different levels of policy implementation, it examines extant gaps between EMI policy and practice.

\section{English-medium instruction}

English-medium instruction (EMI) programmes, defined as educational programmes in which an academic subject is taught through English in non-Anglophone contexts, is becoming increasingly commonplace worldwide. In this paper, EMI students and teachers are defined as stakeholders studying and teaching subject content through English. This global trend of internationalising HE has been researched extensively in the last 20 years, illustrating that EMI has become ubiquitous in HE worldwide - a trend that is also occurring in Japan (Galloway et al. 2017). The majority of EMI research has been carried out in Europe, where significant expansion of EMI degree courses has been well documented (Wächter and Maiworm 2014). Outside Europe, national policies that promote the internationalisation of HE have seen an EMI boom emerging in East Asia (Doiz et al. 2011; Rose and Galloway 2019). The Chinese Ministry of Education has given a national directive to increase EMI undergraduate programmes from 5 to $10 \%$ at all state university programmes by 2013 (Hu et al. 2014). Similarly, in Japan, recent higher education policies have been developed which aim to attract high-quality researchers, teachers and students from abroad (Doiz et al. 2011; Rose and McKinley 2018).

\section{Key language-related issues in EMI globally}

Although EMI has been expanding dramatically, researchers (e.g. Hellekjær 2010; Macaro 2018) have highlighted concerns surrounding EMI implementation. These issues frequently stem from newness (HE policies are still in their infancy), and, crucially, revolve around teachers' and students' English proficiency, which has impeded the successful implementation of EMI (Tsuneyoshi 2005; Hamid et al. 2013). Recent studies (e.g. Hu et al. 2014) that explore 
stakeholders' views on EMI implementation have shown that the drive for EMI is generally top-down, and that gaps exist between macro-level EMI policy and micro-level practice. This is an unsurprising result of initiatives being produced by university administrators and policy makers rather than grassroots-level stakeholders (Botha 2013). It is common for policy makers to see EMI in HE as a useful mechanism for enhancing both students' English ability and content knowledge (Ali 2013), which is a stance challenged by numerous studies (e.g. Chapple 2015; Hu et al. 2014; Kung 2013).

One of the most oft-reported issues regarding EMI implementation is the role of other languages used in instruction. On the face of it, this might appear odd, yet in various EMI settings, it has been shown that stakeholders' language of instruction does not necessarily mean English-only instruction (Botha 2013; Hu et al. 2014; Borg 2015). The findings are supported by a recent survey of EMI in Japan and China which indicated that the students' first language was often used alongside English in most English-taught courses, with great variability between institutions and teachers (Galloway et al. 2017).

Recently, researchers have postulated that the insufficient English proficiency among EMI students is one of the most recurrent obstacles of EMI implementation (e.g. Costa and Coleman 2012; Hamid et al. 2013; Hu et al. 2014; Chapple 2015). Students' linguistic challenges have been noted in a growing body of literature, such as difficulty in taking notes from academic texts (Andrade 2006), comprehending lectures (Hellekjær 2010), understanding teachers' accents (Tange 2010) and understanding academic texts due to insufficient vocabulary knowledge (Kırkgöz 2005). Lin and Morrison (2010) conducted a large-scale study $(n=762)$ at an EMI university in Hong Kong, concluding that only $1.4 \%$ of students from a Chinese medium high school background reached a satisfactory level of productive academic vocabulary knowledge needed to understand lectures and cope with reading assignments. A follow-up 1-year longitudinal study of 3000 students at the same university indicated that language insufficiencies impeded students' comprehension of teachers, discussions and textbooks (Evans and Morrison 2011).

While students' proficiency level is one factor affecting EMI policy implementation, teachers' proficiency levels in English present another barrier. Noted linguistic challenges include teachers' reduced ability to use accessible language (Tange 2010), the lowering of academic content quantity and depth (Chapple 2015) and increased workload and preparation time due to limited language ability (Tsuneyoshi 2005). One study in Iraq provided both quantitative and qualitative evidence of a gap between EMI teachers' necessary English proficiency and their actual proficiency, concluding that EMI implementation was challenging even for highly proficient teachers (Borg 2015).

\section{Higher education policy in Japan}

In 2014, Japan's education ministry announced the recent HE initiative, the TGUP, a 10-year, multimillion dollar investment initiative with the aim 'to enhance the international compatibility and competitiveness of higher education in Japan', and to offer 'prioritized support for the world-class and innovative universities that lead the internationalization of Japanese universities' (MEXT 2014). MEXT selected a total of 37 Japanese universities and provided the annual funding for the 13 universities as Type A (JP¥420m, US $\$ 3.5 \mathrm{~m}$ ), which are viewed as research-oriented universities that are expected to become ranked as top 100 world universities, and 24 universities as type B (JP¥172m, US\$1.4m), identified as innovative universities' that can lead the internationalisation of Japanese society. It is at the type B universities where EMI growth is expected to be more prominent. 
The characteristics of the TGUP have been reported previously in this journal by Rose and McKinley (2018) who conducted an in-depth policy analysis of the initiative in comparison with other preceding policies. The study revealed that, largely speaking, each university had interpreted the TGUP differently and created proposals based on their own interpretations of policy goals. The study notes two limitations in its findings in that

1. The study analysed policy at the macro level only, and thus more research on how policy manifests in practice at the institution level (meso) and classroom level (micro) was needed

2. The study looked at English-medium documents only at each institution, stating that Japanese-language documents could reveal important differences

Rose and McKinley (2018: 17) explicitly state that follow-up 'field research at participant universities of the TGUP is an essential next step in order to examine how these objectives manifest into actions'. Brief reports about the TGUP and its subsequent impact on HE have been published by several researchers, organisations, and governments; however, little to no in-depth research has been conducted to investigate how the TGUP is being operationalised by the universities.

It has been observed that 'Japan provides a valuable context for investigating EMI challenges' (Bradford 2016: 3) as gaps between policy and practice are likely in this HE setting. Wilkinson (2015: 2) also emphasises a possible gap in Japan, claiming that although the Ministry of Education is pushing through fundamental and rapid reforms to its EMI, 'the Japanese Ministry of Education has still not made it clear to teachers and administrators how the new policies should be implemented'. The current study thus aims to fill this gap in the literature by analysing how a recent EMI policy is enacted in practice, as reported by an EMI university and its stakeholders.

\section{The study}

\section{Research questions and framework}

The study aimed to explore the following research questions:

1. In regard to EMI, how is the macro-level TGUP being interpreted by a participant university as reported in meso-level policy?

2. How is the meso-level policy being enacted and implemented in this university at the micro-level, as reported by teachers and students?

3. Does a gap between meso-level and micro-level policy implementation exist?

The framework of the current study is illustrated in Fig. 1, dividing policy into three levels of policy implementation: national (macro), university (meso), and classroom (micro). Rose and McKinley (2018) have already researched the policy at the macro (national) level to identify the main themes of the TGUP initiative; therefore, the current study examines the meso and micro levels to fill this current gap in knowledge.

The current study primarily uses a qualitative single case study approach to deal with the complex, multi-faceted issues pertaining to what happens on the ground. An extensive and 


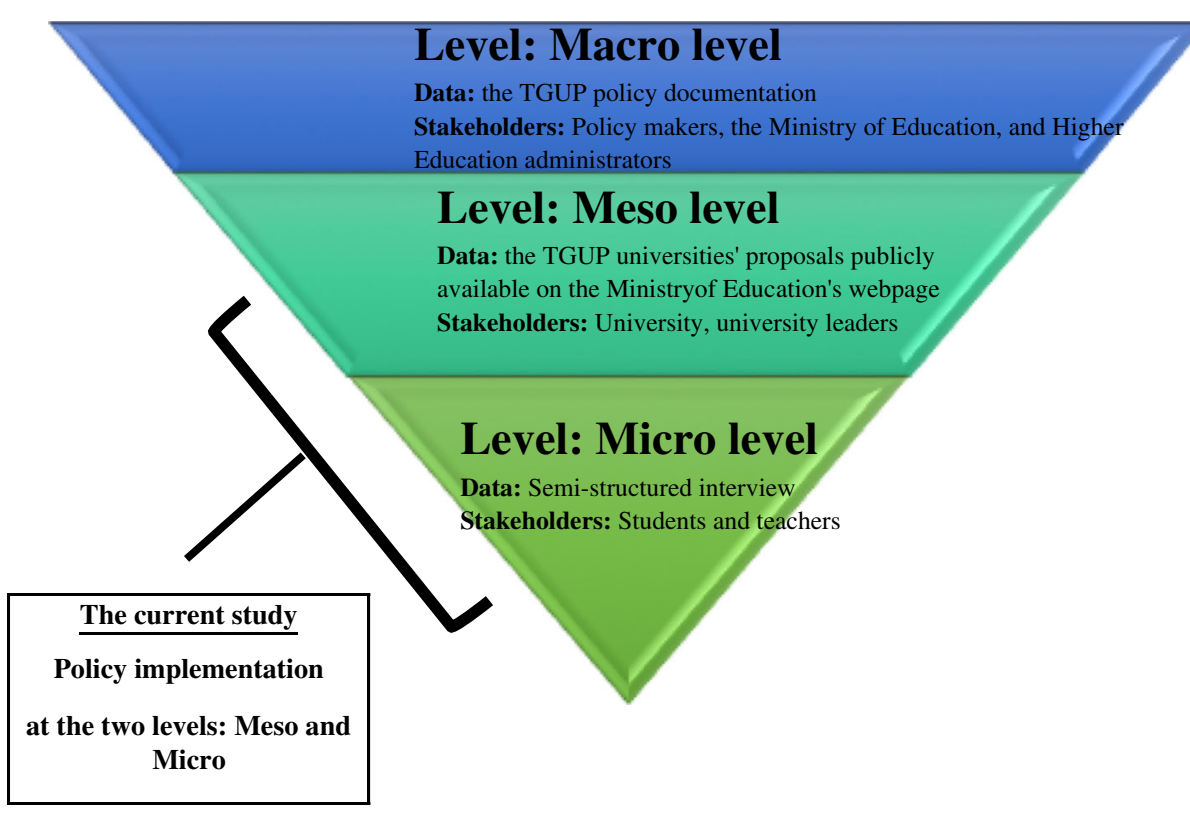

Fig. 1 Policy implementation at the three levels (macro, meso and micro level)

rapidly growing literature (e.g. Hu et al. 2014; Borg 2015) has suggested that policy-oriented studies should use more qualitative approaches to reveal local knowledge of policy implementation presented by stakeholders (e.g. teachers and students). This call is also in line with Rose and McKinley's (2018) call for field work at TGUP participant universities. To display transferability of our qualitative findings, we also provide additional quantitative data from a larger participant pool at the same university, although this dataset is not the primary focus of this paper.

\section{Setting and participants}

The case university, which is situated in the greater Tokyo metropolitan area, was chosen for the following reasons:

1. It was identified in the Rose and McKinley (2018) study as a university that emphasised language development, and thus offered potential to explore language-related issues

2. The university has a strong tradition of bilingual education, offering a number of EMI courses

3. Students across the entire university are required to take at least nine units of EMI courses (i.e. three modules) as a part of their graduation requirement. Previous research at another TGUP university in Japan (McKinley 2018) had indicated variability between EMI within the one university; thus, this university provided more uniform EMI provision.

The study employed maximal variation sampling which 'only investigates a few cases but those which are as different as possible to disclose the range of variation in the field' (Flick 2009: 123). For student case sampling, language proficiency and year level were deemed important variables as they affect students' EMI experiences (e.g. Evans and Morrison 2011). 
Based on background questionnaires from potential participants, the study purposively selected seven students as individual cases that would offer the broadest picture. Table 1 displays the selected cases, with pseudonyms replacing participants' actual names. It is important to note that although the researcher initially aimed to obtain nine cases that would provide three proficiency levels within each year band, only seven suitable participants were recruited due to difficulties in gaining access.

For faculty members, seniority was seen as an important criterion influencing authoritative power over policy implementation. Thus, the sample included one head of department, one professor, and one lecturer. Table 2 provides details of each of these cases.

\section{Data collection}

Three sources of data were used in the study: (1) university TGUP policy documentation, (2) semi-structured interviews with faculty members, and (3) semi-structured interviews with students. In order to explore transferability of the findings to a wider population, the researchers also collected data from 108 students via a questionnaire at the case university, and also compared results to a recent EMI survey of students and staff at five TGUP universities, conducted by Galloway et al. (2017).

The policy documents were collected from the public website of the Japan Society for the Promotion of Science and constituted the official application by the university for the TGUP initiative. The document was published in Japanese and significantly expanded on the amount of policy analysed in Rose and McKinley's (2018) study, which only used the English version for analysis. The Japanese version contained 80 pages. Semi-structured interviews were conducted with all participant teachers and students in order to investigate stakeholder interpretations and implementation of policy at the micro level. All the interviews were conducted entirely in Japanese to improve reliability of data, as interviewees are more likely to provide accurate responses when interviewed in their L1. The interviews lasted approximately 40 minutes for students and 30 minutes for faculty members and were recorded for transcription and textual analysis. The interview schedule was adapted (with permission) from that used in a similar study in a Malaysian EMI context, which investigated policy implementation at various levels (Ali 2013). Data from the policy documents and the interviews were compared to reveal any extant gaps in policy and practice.

Table 1 Information of students (source: student interviews)

\begin{tabular}{lllll}
\hline Participants & Year & Gender & Proficiency (CEFR) & Major \\
\hline Tomoya & 1 & Male & A2 (low)* & N.A.** \\
Ryo & 1 & Female & C2 (high)* & N.A.** \\
Minami & 2 & Female & A2 (low)* & N.A.** \\
Asuka & 2 & Female & B1 (middle) & N.A.** \\
Kohei & 3 & Female & A2 (low)* & Sociology \\
Daisuke & 3 & Male & B1 (middle) & Economics \\
Mikiko & 3 & Male & C2 (high)* & Biology \\
\hline
\end{tabular}

*Students indicated their level of English proficiency on the short-background questionnaire, such as their TOEFL score. TOEFL PBT 600 above $($ CEFR C1 levels $)=$ high proficiency, 450-600 (CEFR B2/B1 Levels) = middle proficiency, 350-450 (CEFR A2 Levels) = low proficiency

**At the university, students do not decide their main major(s) until their third year 
Table 2 Information of teaching faculty members (source: staff interviews)

\begin{tabular}{lllll}
\hline Participants & Position & Gender & Proficiency & Department \\
\hline Atsuki-sensei & Director of department & Female & High $(\mathrm{C} 2)^{* * *}$ & Linguistics \\
Yujo-sensei & Professor & Male & High $(\mathrm{C} 2)^{* * *}$ & Business \\
Seyo-sensei & Lecturer & Male & High $(\mathrm{C} 1)^{* * *}$ & Sociolinguistics \\
\hline
\end{tabular}

***Faculty members' self-rated English proficiency according to CEFR

\section{Data analysis}

Coding of data followed the process of 'qualitative content analysis', sometimes referred to as 'thematic qualitative text analysis' (Kuckartz 2014), which has been used in similar policyoriented studies (e.g. Rose and McKinley 2018). As this analysis generally requires data that are transformed into written text, the lead researcher transcribed all the interview data verbatim. The current study thus combined both the inductive and deductive approaches. A start list of topical categories was initially constructed deductively based on Rose and McKinley (2018) macro-level EMI policy analysis, and then codes were developed inductively from the empirical data themselves. A provisional list of these initial categories was constantly checked within the data and amended as new concepts emerged through the initial or later cycles of coding.

\section{Results}

Policy documentation indicated that the university planned to increase the number of EMI courses from 16.5 to $40.0 \%$ during the period between 2013 and 2023 (see Table 3). Increasing the provision of EMI courses offered at the university was described in policy documents as 'one of the most critical issues faced by the university in the process of its internationalisation'. As our research questions centred on the language planning implications surrounding this growth in EMI, we present our coded data under four broad language-related themes:

1. Issues surrounding the language used as the medium of instruction

2. Issues stemming from students' language proficiency

3. Language-related challenges experienced by EMI students

4. Issues stemming from teacher language proficiency and EMI training

Table 3 The number of classes taught in foreign languages or in English (source: policy data)

\begin{tabular}{lcccc}
\hline & 2013 & 2016 & 2019 & 2023 \\
\hline Number of classes taught in a foreign language (A) & 248 & 353 & 449 & 568 \\
Number of classes taught in English (B) & 240 & 345 & 441 & 560 \\
Number of classes taught at the university (C) & 1451 & 1400 & 1400 & 1400 \\
Proportion (B/C) & $16.5 \%$ & $24.6 \%$ & $31.5 \%$ & $40.0 \%$ \\
\hline
\end{tabular}




\section{Languages used in EMI contexts}

'Language of instruction' was one of the most heavily coded themes in the analysis of the TGUP policy document, with 167 references in total. University policy dictated that the language of instruction of all of its programmes must be explicitly categorised and labelled in its online syllabus as $\mathrm{J}, \mathrm{E}, \mathrm{J} / \mathrm{E}$ or E/J, according to whether Japanese, English or a mix of both languages were used. The policy also explained that in E or J courses, lecturers and students should only use English or Japanese respectively within all course domains (emphasis our own). In J/E and E/J courses, on the other hand, teachers had flexibility to use Japanese and English (or English and Japanese) as a principle and supplementary classroom language.

Based on data from the interviews; however, it was found that the reality of classroom language use appeared to be far more complicated than policy indicated. These discrepancies were evident in all of the interviews conducted, and an illustrative excerpt from one student interview is provided below:

I took a philosophy course which was supposed to be offered entirely in English, but the course was actually taught in both English and Japanese. I remember I was quite relieved in my first class when my teacher gave us the syllabus of the course. The course was labelled as $\mathrm{E}$ on the online syllabus I had checked during the course registration period, but the syllabus that I was given in the first class stated that some tests and quizzes were conducted in Japanese. Throughout the course, I realised that the teacher was originally from America but luckily very fluent in Japanese. I was even allowed to submit all my assignments in Japanese if I preferred. (Minami, Low A2, 2nd year student)

Thus, despite the language of instruction being indicated as English only on the syllabus, Minami observed that both languages were used in a flexible manner.

In the same vein, one teacher also revealed how the two languages are mixed in EMI courses, in spite of policy stipulations:

When I teach my classes that are labelled as E, I normally try to use only English. Otherwise, it is not an E course. But I sometimes hear from other Japanese instructors that their students often use Japanese in their English-conducted courses. They believe there is no point using English to ask questions or give presentations when the majority of their classmates are Japanese. (Yujo-sensei, Business professor)

Table 4 summarises three examples from each course type, which emerged from interview data. These results indicate all course types deviated from policy document stipulations, with Japanese used in E-marked course, English used in J-marked courses and little difference between $\mathrm{E} / \mathrm{J}$ and $\mathrm{J} / \mathrm{E}$ in terms of the dominant language used.

Evidence from teacher interviews also showed discrepancies regarding language use in Elabelled classes. Yujo-sensei (Business Professor) believed that E courses must be conducted entirely in English while Atsuki-sensei (Head of Department) argued that Japanese should also be used if it would be beneficial for students' academic knowledge. Findings further indicated that there was no guidance on the policy to suggest how much Japanese and English should be used in $\mathrm{E} / \mathrm{J}$ or $\mathrm{J} / \mathrm{E}$ courses. As a result, teachers based their decisions on vastly different criteria. One teacher participant (Seyo-sensei, Linguistics Lecturer) stated, 'I sometimes find it difficult to decide how much English or Japanese I should use in my $\mathrm{J} / \mathrm{E}$ and $\mathrm{E} / \mathrm{J}$ classes'. Another teacher (Yujo-sensei, Business Professor) stated that the decision as to which language he uses is based on what subject he teaches and whether written materials are available in English. 
Table 4 The language of instruction reported by students (source: student interviews)

\begin{tabular}{|c|c|c|c|c|}
\hline $\begin{array}{l}\text { Medium of instruction } \\
\text { on syllabus }\end{array}$ & $\mathrm{J}$ & $\mathrm{J} / \mathrm{E}$ & $\mathrm{E} / \mathrm{J}$ & $\mathrm{E}$ \\
\hline Data source & Ryo & Asuka & Mikiko & Minami \\
\hline Course & $\begin{array}{l}\text { Constitutional } \\
\text { studies }\end{array}$ & Cultural studies & $\begin{array}{l}\text { Japanese } \\
\text { linguistics }\end{array}$ & Philosophy \\
\hline Lecturer's L1 & Japanese & Japanese & Japanese & English \\
\hline Lecture & Japanese & Japanese & English & English \\
\hline Material & $\begin{array}{c}\text { English and } \\
\text { Japanese }\end{array}$ & Japanese and English & Japanese & $\begin{array}{c}\text { English and } \\
\text { Japanese }\end{array}$ \\
\hline Group work & Japanese & N/A & Japanese & Japanese \\
\hline Assignment & English & $\begin{array}{l}\text { Japanese (English } \\
\text { OK) }\end{array}$ & Japanese & $\begin{array}{l}\text { English } \\
\quad \text { (Japanese OK) }\end{array}$ \\
\hline Exam & English & $\begin{array}{l}\text { Japanese (English } \\
\text { OK) }\end{array}$ & Japanese & $\begin{array}{l}\text { English } \\
\quad \text { (Japanese OK) }\end{array}$ \\
\hline
\end{tabular}

Atsuki-sensei (Director of Department of Linguistics) stated he based this decision on whether the students were able to understand him, so 'I would use Japanese even in my Englishconducted courses if they could understand me better'.

Overall, the reality of actual classroom language use was far more complicated than the policy indicated and depended upon several factors including stakeholders' language proficiencies, classroom activities, teaching materials, lecture content, and academic disciplines. It was also found that the respondents all had their own interpretations of how language policy was to be enacted into practice, especially in $\mathrm{E} / \mathrm{J}$ and $\mathrm{J} / \mathrm{E}$ courses.

\section{Students' English proficiency}

One category only lightly coded in the policy documentation, but heavily evident in all interview data, was students' English proficiency, discussed as a crucial factor in determining students' success in EMI courses. In an analysis of the policy documentation, findings revealed that the university proposed clear targets to increase the number of students reaching a set proficiency threshold of IELTS 6.5 from $38.5 \%$ in 2013 to $50 \%$ by 2023, as can be seen in Table 5. The policy outlined a language development programme, called English as Liberal Arts (discussed later), in order to help students reach this goal.

Despite the university's attempt to improve students' English proficiency by introducing this threshold, the interviewees seemed to view this policy as a double-edged sword: on the one hand, it was seen to provide motivation to achieve a linguistic goal; on the other hand, it was seen as a deterrent to enrol in EMI courses. Examples of these two opposing views are illustrated by Asuka (Intermediate B1, 2nd year student), who stated 'I would be much happier if I knew what sorts of proficiency I needed to achieve to take E courses', contrasted to Ryo (High C2, 1st year student) who stated 'If the threshold is introduced, I think my friends who

Table 5 The number of students who have >IELTS 6.5 after ELA (source: policy data)

\begin{tabular}{lllll}
\hline & 2013 & 2016 & 2019 & 2023 \\
\hline Number of students at/over threshold (A) & 1076 & 1137 & 1222 & 1391 \\
Number of students (B) & 2797 & 2774 & 2779 & 2784 \\
Proportion (A/B) & $38.5 \%$ & $41.0 \%$ & $44.0 \%$ & $50.0 \%$ \\
\hline
\end{tabular}


are not good at English would be discouraged to attend any single EMI course'. Arguing against this threshold policy, Yujo-sensei (Business Professor) provided the following view:

I don't think it's necessary to have the threshold as the difficulty of each course is determined by not only the fact that courses are run in English but also other factors, like course activities, the number of assignments and how strict the teacher is. I remember one of my students who was not good at English still did very well in my class.

This sentiment was similar to a view expressed by a student (Mikiko, High C2, 3rd year student) that proficiency scores did not always indicate whether a student could do well in an EMI course.

Many students claimed that they had experienced a number of linguistic challenges due to their insufficient English ability. One student claimed:

I have difficulty achieving good grades in E courses due to my poor English. My English is not very good and I find it impossible to attend EMI lectures and focus on listening to my teacher speaking in English for more than 50 minutes (Kohei, Low A2, 3rd year student).

Another lamented the amount of reading required for E courses every day, stating 'I take too much time to complete all my required reading' (Tomoya, Low A2, 1st year student). Even Ryo (High C2, 1st year student), who was the highest-proficiency student in the sample, expressed concerns about EMI, and the heightened challenges of studying through English.

\section{Language-related challenges of EMI students}

Linguistic challenges were coded for all student participant interviews, regardless of their English proficiency. However, lower-proficiency students exhibited a wider range of challenges, which centred around a lack of both academic skills and language-related skills. Higher-proficiency students noted problems such as the amount of writing required and essay organisation skills. Intermediate-proficiency students (CEFR B1) mentioned additional challenges such as reading long texts, understanding technical vocabulary, comprehending accented English and asking questions. Lower-proficiency students (CEFR A2) further mentioned fundamental language-related challenges such as understanding teachers, participating in discussions, taking notes, listening to lectures and comprehending unfamiliar grammar structures. Thus, findings drawn from the current sample indicated a relationship between students' language proficiency and the type of linguistic challenges. Higher-proficiency students tended to face specific academic literacy challenges, whereas lower-proficiency students encountered language difficulties. There was no indication that challenges were defined according to the year level of the participant. Thus, we conclude that prolonged experience learning in an EMI context did not alleviate the burdens faced by students.

The policy documentation detailed a structural provision intended to provide learners with language and academic development. The university offered an academic English-language programme, referred to as the 'English as Liberal Arts (ELA)' programme, which was a mandatory intensive English-language programme for first and second year domestic undergraduate students who came from Japanese-based high school systems and was designed to help students prepare for EMI courses in their chosen academic subjects.

However, despite taking part in the intensive programme (ELA), students claimed that ELA only helped them improve specific aspects of their academic English (e.g. writing) rather than the overall English skills needed for EMI. As an illustrative comment, Kohei (Low A2, 3rd year student) stated: 
I don't know if ELA was helpful to improve my overall English skills. I feel ELA was only beneficial in improving my reading skills by reading many English articles. I don't think I improved much in other skills, like speaking, listening and writing, which I also need for EMI.

This sentiment was shared by Mikiko (High C2, 3rd year student) who said while ELA helped to improve the productive aspects of academic English, listening remained a challenge during her EMI courses. All other students reported that attending ELA classes was only beneficial to improve specific areas of academic English proficiency, predominantly their reading and writing skills, rather than fully preparing them for EMI.

In addition to these students' views, teachers also highlight a gap between skills taught in ELA and skills needed for EMI:

In my opinion, some students do not have sufficient English skills to take Englishconducted courses even after they have taken ELA for two years. Students that are placed in lower English-proficiency groups would need more time improving their English before taking E courses. These students would learn less than their counterparts without sufficient English. (Yujo-sensei, Business Professor)

Atsuki-sensei (Head of Department) observed that there was 'a gap between ELA and EMI', where EMI posed a challenge for lower proficiency students. Thus, findings suggest difficulties for students to accomplish a smooth transition from one programme to the other, despite indications in policy documentation that such support would be sufficient.

\section{Teacher language proficiency and training}

Faculty members' English proficiency was another theme particularly prominent in the interview data but not heavily coded in policy documentation. Policy documentation only briefly touched upon teacher proficiency in the criteria it outlined for newly appointed faculty members. The recruitment criterion for appointment of new EMI lecturers stated: 'Applicants must be able to conduct lectures and tutorials in both Japanese and English'. The policy further stated that applicants were normally required to give a demonstration lesson as part of the university's recruitment procedure to showcase his or her ability to conduct a course in both English and Japanese. However, there was no guidance regarding the level of English proficiency required to demonstrate this ability.

Five students explained that they had experienced difficulty in understanding lecture content due to instructors accented or poor English, as illustrated by the following except:

I had difficulty in understanding what my lecturer was saying because of his thick

Japanese accent.... He assigned a lot of reading materials written in Japanese, so I wish he also had used Japanese when conducting lectures. (Mikiko, High C2, 3rd year student)

However, another student stated they preferred non-native EMI teachers stating that 'I sometimes notice that courses taught by a native English speaker are more fast-paced and use more difficult vocabulary. So, I prefer courses taught by non-native English speakers' (Daisuke, Intermediate B1, 3rd year student). However these students also observed that 'the quality of these courses are lower because of the level of teachers' English proficiency'. Table 6 outlines a summary of additional concerns over teacher proficiency. 
Teachers also observed language-related challenges associated with delivering EMI classes. Seyo-sensei (Linguistics Lecturer), who had only studied and taught in Japan, mentioned problems with his English when conducting EMI courses, including a need to speak more slowly, coupled with increased time pressure to prepare EMI lectures. Yujo-sensei (Business Professor), who completed his $\mathrm{PhD}$ in an English-speaking country, also indicated issues surrounding EMI:

There are some drawbacks of teaching in English. I have to spend much more time on preparation for my class. In English there are certain topics I'm not comfortable teaching, whereas in Japanese I can teach almost anything freely in my field. The quality of E courses taught by a Japanese teacher can easily be lower.

Thus, although some interviewees described teachers' English proficiency as one of the factors impeding students' ability to understand EMI lectures, overall, there appears to be little discussion about the assessment of EMI teachers and the English proficiency required of teachers.

Policy document analysis revealed that the university offered a support policy to provide teacher training opportunities for faculty members. That is, nominated faculty members were given an opportunity to attend teacher training programmes to improve their teaching skills required for EMI programmes. Despite this provision, all three teacher participants had not made use of it, or were unaware of it. One teacher explicitly stated, 'I don't think the university offers enough support opportunities for teaching staff' (Seyo-sensei, Linguistics Lecturer), indicating that the support policy was not be widely promoted beyond the policy document.

\section{Generalisability of findings}

Overall, results of this case study revealed gaps in policy implementation when diffused from the meso to micro level and is summarised in a reduced format in Fig. 2.

While our in-depth multiple case study intended to leverage the benefits of qualitative research, the limited size of our sample draws into question whether our findings are generalisable to the broader university context. In order to demonstrate transferability of our findings, we now draw on further data to corroborate findings. This data include

Table 6 Problems regarding teachers' English proficiency (source: student interviews)

\begin{tabular}{|c|c|c|c|}
\hline Source & Course & $\begin{array}{l}\text { Lecturer's } \\
\text { L1 }\end{array}$ & Problems \\
\hline Mikiko & Japanese linguistics & Japanese & $\begin{array}{l}\text { - Lecturer had a strong foreign accent. } \\
\text { - Lecturer used Japanese when he could not find English words. }\end{array}$ \\
\hline Daisuke & Gender and sexuality & Japanese & $\begin{array}{l}\text { - Lecturer only used simple English words. } \\
\text { - Lecturer spoke too slowly. }\end{array}$ \\
\hline Tomoya & Linguistics & Chinese & - Lecturer had a strong foreign accent. \\
\hline Minami & Translation studies & Japanese & $\begin{array}{l}\text { - Lecturer had a strong foreign accent. } \\
\text { - An exam paper was written in poor English. }\end{array}$ \\
\hline Kohei & Global studies & Japanese & $\begin{array}{l}\text { - Lecturer had a strong foreign accent. } \\
\text { - Lecturer was reading everything from notes. }\end{array}$ \\
\hline
\end{tabular}




\section{Language of instruction}

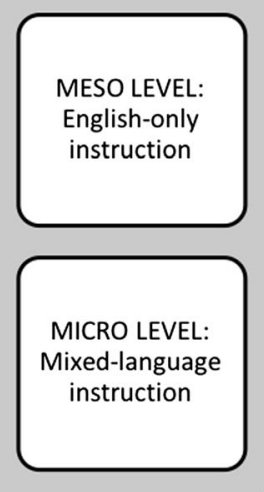

Students'

English proficiency

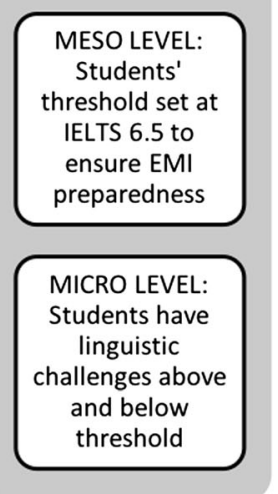

Teachers'

English proficiency
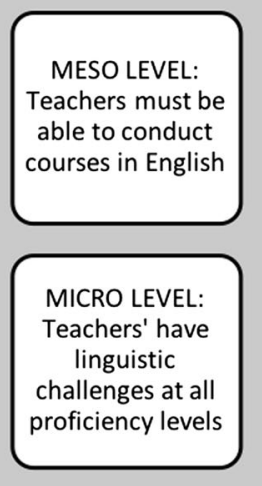

English

language support

MESO LEVEL:

Language support

in preparatory

ELA is sufficient for EMI study

MICRO LEVEL:

Students need continued

support

throughout EMI

Fig. 2 A gap in EMI implementation between the meso and micro level

- Related items from a larger dataset, collected by the researchers, which consisted of 108 questionnaires with students at this university

- Data extracted from a British Council report (Galloway et al. 2017), which were collected at five TGUP universities, including our case university

\section{Language of instruction}

In terms of our finding that there was mixed-language instruction in the implementation of EMI courses at our case university, this finding is supported by Galloway et al.'s (2017) report. An analysis of just the Japanese data in their study revealed that $71.7 \%, 73.4 \%$ and $78.7 \%$ of students agree that their lectures, materials and exams respectively are 'always in English'. This study also revealed differences across universities, indicating the results of our study may be different from other TGUP institutions. This suggests that further fieldwork at other TGUP universities is needed to understand the full extent of EMI practices within participant universities.

\section{Language-related challenges}

In order to check the generalisability of the language-related challenges in our qualitative sample with our case university's wider student population, a survey of 108 university students measured EMI-related challenges via a 21-item questionnaire organised around the four language skills. The questionnaire was adapted from Evans and Morrison's (2011) examination of challenges in the Hong Kong EMI context. A Mann-Whitney $U$ test was applied to the non-normally distributed data to ascertain whether students above the threshold of IELTS 6.5 experience significantly fewer problems than those below the 6.5 threshold. Descriptive statistics of the scores of academic English between two groups are presented below, ranging from 1 (very difficult) to 5 (very easy). A Mann-Whitney $U$ test was employed to examine whether the means were significantly different between the groups (see Table 7 below for the 
differences in the mean scores in the groups). The results revealed that the mean scores of students with IELTS 6.5 and above differed significantly $(p<.001)$ from their counterparts in all the four language skill areas of speaking $(U=436.5, \mathrm{z}=-6.582)$, writing $(U=740.0, \mathrm{z}=$ $-4.882)$, listening $(U=668.5, z=-5.283)$, and reading $(U=600.0, z=-5.667)$. Students with higher proficiency found their challenges less difficult than their counterparts. Nevertheless, with median scores above 2.5 for both groups, the findings of the qualitative findings that groups reported problems below and above the proficiency level was supported.

\section{English language support}

To further explore the notion of language support, we investigated the relationship between the students' challenges and their proficiency using the Spearman correlation test, applied to the data above. The results showed that students' English proficiency was positively correlated with the language-related challenges associated with writing $(r=.451, p<.001)$, reading $(r=.524$, $p<.001)$, speaking $(r=.608, p<.001)$ and listening $(r=.488, p<.001)$. This indicates a relationship between proficiency and EMI challenges, where the higher a students' language skills, the less EMI challenges they face. This suggests that all students would benefit continued language support throughout their EMI studies, rather than only below a policy-mandated threshold.

Galloway et al. (2017: 16) reported that Japanese students at TGUP universities believe that 'classes should be supplemented with English-language support classes provided by English teachers $(\mathrm{M}=3.0, \mathrm{SD}=0.6)^{\prime}$, which was consistent with staff responses $(\mathrm{M}=2.9, \mathrm{SD}=0.9)$ in the study. Thus, this data also supports the notion that EMI programs which offer continued language support throughout EMI study are preferable for students and teachers alike. Based on our qualitative results, coupled with support from this additional data, the relationship between proficiency and EMI challenges warrants further research.

\section{Teacher proficiency}

Galloway et al. (2017), in her investigation of EMI programmes in Japan, discovered many students perceived their teachers' lack of English language proficiency to be a challenge for effective teaching, while the teachers perceived the linguistic challenges were due to the students' lack of proficiency. Looking beyond this study, Bradford (2012) interviewed 27 members of three Japanese EMI universities and found that most faculty members expressed language-related limitations when using English for teaching content, as well as longer preparation time for delivering a good lecture. Thus, while additional evidence exists to support generalising our qualitative findings, extant evidence on teacher-related EMI challenges is piecemeal within the Japanese context, and thus warrants further investigation.

Table 7 Descriptive statistics for challenges of students above and below IELTS 6.5

\begin{tabular}{llllllll}
\hline & \multicolumn{2}{l}{ At or above threshold $(n=43)$} & & & \multicolumn{2}{l}{ Below threshold $(n=75)$} \\
Skill (mean of means) & Mean & Median & SD & & Mean & Median & SD \\
\hline Writing skills & 3.48 & 3.67 & 0.72 & & 2.73 & 2.73 & 0.70 \\
Reading skills & 3.54 & 3.60 & 0.72 & & 2.63 & 2.60 & 0.74 \\
Speaking skills & 3.64 & 3.80 & 0.69 & & 2.59 & 2.50 & 0.71 \\
Listening skills & 3.70 & 3.90 & 0.70 & & 2.87 & 3.00 & 0.82 \\
\hline
\end{tabular}




\section{Discussion, implications and conclusions}

Researchers (e.g. Ali 2013) have emphasised similar gaps in other EMI contexts, claiming that policy makers insist on implementing EMI policy for reasons of economic development and improved global status without considering stakeholders' challenges, demands and available resources required to ensure successful EMI implementation. Certainly, in our case university, issues such as explicit language of instruction, sufficiently trained teachers, support provisions and language assessment have not been sufficiently considered by those at the top (meso), resulting in discrepancies in practice (micro). Our data reveal one of the most apparent factors causing difficulties for teachers to enact policy within practice revolved around a lack of detailed information of the initiative itself, leading to the inconsistent interpretation by policy actors. For example, whilst the university aims to increase the number of English-medium courses, it does not articulate what constitutes EMI in their policy document; consequently, faculty members have their own criteria to determine the amount of Japanese used in their EMI classes. Thus, a cause for the gap in policy and practice may stem from poorly articulated meso-level policy, which seeks to meet somewhat abstract objectives of the macro-level policy. As a result, universities seek to appease MEXT by showing numerically measurable EMI growth and internationalisation in other sectors of the university, rather than focusing on the contextualised micro-level implementation challenges. The implications for this research may require universities to reconsider unrealistic language proficiency targets and proposed increases in EMI programme numbers, lest they risk improper implementation at the micro level due to linguistic and pragmatic constraints. This will ensure future policy is informed by both top-down wants and bottom-up needs.

The current study also indicated that EMI teachers expressed difficulty in teaching in English, regardless of the level of their English proficiency. In other words, even high proficiency teachers at this case reported linguistic challenges. This finding does concur with research findings by Borg (2015) that highly proficient teachers in Iraq stated EMI implementation was challenging due to limited linguistic abilities. Thus, teaching challenges may be more pervasive in emerging EMI contexts, such as Japan and the Middle East, than in more mature contexts like Northern and Western Europe. Such findings indicate a need for EMI teacher training, because merely being proficient in English and being an expert in a subject area does not indicate that a lecturer is qualified to teach that subject area in an EMI setting.

In order to facilitate policy into practice, many researchers have suggested the importance of institutional and governmental support for stakeholders (e.g. Lin and Morrison 2010; Borg 2015), particularly regarding language. Our study supports such assertions. Currently, however, there are few organisational or pedagogical guidelines which explicitly state expectations of English ability of EMI instructors in many EMI contexts. In Japan, Wilkinson (2015) summarised the EMI provisions of one EMI university, claiming that although the government has pushed through HE policies to promote EMI, very little pedagogical training appears to have been offered to EMI teachers working under these new policies. This finding is startling considering a recent study by Leong (2017) revealed teacher training was a critical issue expressed by EMI teacher participants to address linguistic challenges in HE. In the case of our three participant teachers, although some EMI training had been made available, there was little uptake due to a lack of knowledge of the resources available.

Furthermore, in line with the scholarly literature (e.g. Lin and Morrison 2010), students in the current study indicated that while language proficiency played a role in the types of challenges experienced by students, all students experience difficulties. At the meso level, 
it was found that the university in the present study introduced a linguistic threshold (IELTS 6.5) to ensure that students could fully take advantage of EMI courses. In contrast to this clear-cut threshold, Ali (2013) identified vague criteria for students' language proficiency on the Malaysian university's policy, stating that students must have 'excellent English proficiency', and 'the ability to communicate in English through their academic courses' (p. 80) in order to study through EMI. Given the high level of English skills required to study in English (Mori 2011), the explicit threshold policy of our case university seems more appropriate considering the Malaysian case showed that implicit policy is poorly interpreted and is unhelpful in determining whether students were ready for EMI study. Nevertheless, these findings concur with other research in EMI contexts in Japan, which have found that even when English proficiency is high, academic tasks such as engaging in discussions about complex ideas can still be very challenging (McKinley 2018). Such findings highlight the need for sustained language support throughout EMI programmes, rather than providing support in a preparatory-style manner. These findings have wider implications for EMI contexts throughout Asia and the Middle East, where preparatory-style EMI models are pervasive (Macaro 2018).

\section{Limitations and calls for further research}

One limitation of the current study is the use of indirect data collection instruments as a principal method to examine the views and practices of stakeholders, as opposed to direct methods. Borg (2015) claims that without direct methods, it is difficult to provide an accurate picture of stakeholders' views. It should also be noted that, despite calls for contextualised case study research on-the-ground (Rose and McKinley 2018), the use of a small sample size inevitably limits the generalisability of the present findings. Moreover, we cannot claim that the students in our context, which includes a high percentage of proficient students, is representative of students' educational experiences at other TGUP institutions. Moreover, as international students were not included in our sample, the voice of this cohort of learners remains unheard in the current study. Thus, we highlight a need to conduct research at other TGUP universities in order to observe whether the same issues are evident, across differing study bodies.

In seeking to explore gaps between policy and practice in one university, the present study has used a synchronic rather than diachronic approach. Although this approach still allowed us to elucidate emerging themes of stakeholders' needs, lacks and desires via one-off interviews, it did not illustrate how their opinions of challenges and gaps might have changed over a period of time. The meso-level policy analysis was conducted on the available policy document of participant universities in terms of how its role in the TGUP initiative was outwardly presented to MEXT as part of the TGUP application. Although the 80-page document summarised the university's strategic plans, we did not find any evidence to suggest that the university had predicted any issues regarding potential gaps between policy and practice at the different levels of policy diffusion. It would be fruitful to explore whether such issues are raised in future incarnations of policy, as well as in publicly available reports based on TGUP initiatives. The need of a longitudinal design in the Japanese HE context is also echoed in Rose and McKinley's (2018) call for future longitudinal research that tracks stakeholders' views and behaviours during policy implementation. 


\section{Conclusions}

It appears that the EMI policy in Japan is being driven by institutional-level and national-level policy, rather than being pushed by students and teachers themselves. This marks a significant departure from earlier forms of EMI in Europe, which emerged as the result of an increasingly mobile European academic student and staff body. Based on this case study, we concur with Kung's (2013: 99) assertion that 'the genuine goal of education should be aimed at students in the first place', and the current study suggests that universities should more actively consider stakeholders' views and practices when creating its EMI policy, which include students and teachers, alongside government officials, policy makers, university leaders, and HE administrators. Given that these various groups and individuals represent different educational aims, it is difficult to determine who should develop HE policy, but all views are central to uniform implementation of policy at the macro, meso and micro levels. This conclusion extends beyond the context of Japan and holds relevance for other nations that are pushing EMI programmes in HE institutions via internationalisation policies, which may result in similar implementation challenges.

As the international EMI literature (Hamid et al. 2013; Macaro et al. 2018) suggests that EMI implementation challenges are globally pervasive despite consistent interest worldwide in expanding EMI programmes, the factors outlined in this article are not only limited to the current Japanese HE context but also have relevance for other international EMI contexts. It is important to bear in mind, however, that EMI policy implementers in different contexts might project different motivations and aims for introducing EMI, and EMI implementation is individually unique due to contextual differences inherent to each EMI setting. Thus, a case study approach, such as the one used in this study, can help HEI policy makers to more fully understand the complex issues that can affect successful EMI implementation at contextualised institutional and classroom levels.

Open Access This article is distributed under the terms of the Creative Commons Attribution 4.0 International License (http://creativecommons.org/licenses/by/4.0/), which permits unrestricted use, distribution, and reproduction in any medium, provided you give appropriate credit to the original author(s) and the source, provide a link to the Creative Commons license, and indicate if changes were made.

\section{References}

Ali, N. L. (2013). A changing paradigm in language planning: English-medium instruction policy at the tertiary level in Malaysia. Current Issues in Language Planning, 14(1), 73-92.

Andrade, M. S. (2006). International students in English-speaking universities: adjustment factors. Journal of Research in International Education, 5(2), 131-154.

Borg, S. (2015). English medium instruction in Iraqi Kurdistan: perspectives from lecturers at state universities. London: British Council.

Botha, W. (2013). English-medium instruction at a university in Macau: policy and realities. World Englishes, $32(4), 461-475$.

Bradford, A. (2012). Adopting English-taught degree programs. International Higher Education, 69, 8-10.

Bradford, A. (2016). Toward a typology of implementation challenges facing English- medium instruction in higher education: evidence from Japan. Journal of Studies in International Education, 20(4), 339-356.

Bradford, A., \& Brown, H. (2018). Introduction: English-medium instruction in Japanese higher education. In A. Bradford \& H. Brown (Eds.), English-Medium Instruction in Japanese Higher Education: Policy, Challenges and Outcomes (pp. xvii-Xiii). Bristol: Multilingual Matters. 
Chapple, J. (2015). Teaching in English is not necessarily the teaching of English. International Education Studies, 8(3), 1-13.

Costa, F., \& Coleman, J. A. (2012). A survey of English-medium instruction in Italian higher education. International Journal of Bilingual Education and Bilingualism, 16(1), 3-19.

Doiz, A., Lasagabaster, D., \& Sierra, J. M. (2011). Internationalisation, multilingualism and English-medium instruction. World Englishes, 30, 345-359.

Evans, S., \& Morrison, B. (2011). Meeting the challenges of English-medium higher education: the first-year experience in Hong Kong. English for Specific Purposes, 30(3), 198-208.

Flick, U. (2009). An introduction to qualitative research. London: Sage Publications.

Galloway, N., \& Rose, H. (2015). Introducing Global Englishes. Abingdon: Routledge.

Galloway, N., Kriukow, J., \& Numajiri, T. (2017). Internationalisation, higher education and the growing demand for English: an investigation into the English medium of instruction (EMI) movement in China and Japan. London: British Council.

Hamid, M. O., Nguyen, H. T. M., \& Baldauf Jr., R. B. (2013). Medium of instruction in Asia: context, processes and outcomes. Current Issues in Language Planning, 14, 1-15.

Healey, N. M. (2008). Is higher education really 'internationalising'? Higher Education, 55(3), 333-355.

Hellekjær, G. O. (2010). Lecture comprehension in English-medium higher education. Hermes: Journal of Language and Communication Studies, 45, 11-34.

Hu, G., Li, L., \& Lei, J. (2014). English-medium instruction at a Chinese university: rhetoric and reality. Language Policy, 13(1), 21-40.

Kırkgöz, Y. (2005). Motivation and student perception of studying in an English-medium University. Journal of Language and Linguistic Studies, 1(1), 101-123.

Kuckartz, U. (2014). Qualitative text analysis : a guide to methods, practice \& using software. London: Sage.

Kung, F. W. (2013). The more the merrier? Bilingualism in an academic perspective: exploring the implementation of English-medium instruction in Taiwanese tertiary education. Asian EFL Journal Research Articles, 4, 8-36.

Leong, P. (2017). English-medium instruction in Japanese universities: policy implementation and constraints. Current Issues In Language Planning, 18(1), 57-67.

Lin, L. H. F., \& Morrison, B. (2010). The impact of the medium of instruction in Hong Kong secondary schools on tertiary students' vocabulary. Journal of English for Academic Purposes, 9(4), 255-266.

Macaro, E. (2018). English medium instruction. Oxford: Oxford University Press.

Macaro, E., Curle, S., Pun, J., An, J., \& Dearden, J. (2018). A systematic review of English medium instruction in higher education. Language Teaching, 51(1), 36-76.

McKinley, J. (2018). Making the EFL to ELF transition in English-medium instruction at a global traction university. In A. Bradford \& H. Brown (Eds.), English-Medium Instruction in Japanese Higher Education: Policy, Challenges and Outcomes (pp. xvii-xiii). Bristol: Multilingual Matters.

MEXT (2014). Selection for the FY2014 Top Global University Project. Retrieved from http://docplayer. net/16379288-Selection-for-the-fy-2014-top-global-university-project-we-hereby-announce- the-selectionof-universities-for-the-top-global-university-project.html.

Mori, J. (2011). G30 and its implications for Japan. Kyoto University International Center Research Bulletin, 1, $63-71$.

Rose, H., \& Galloway, N. (2019). Global Englishes for language teaching. Cambridge: Cambridge University Press.

Rose, H., \& McKinley, J. (2018). Japan's English medium instruction initiatives and the globalization of higher education. Higher Education, 75(1), 111-129.

Tange, H. (2010). Caught in the tower of babel: university lecturers' experiences with internationalisation. Language and Intercultural Communication, 10, 137-149.

Tsuneyoshi, R. (2005). Internationalization strategies in Japan: the dilemmas and possibilities of study abroad programs using English. Journal of Research in International Education, 4, 65-86.

Wächter, B., \& Maiworm, F. (2014). English-taught programs in European higher education. The state of play in 2014. Bonn: Lemmens.

Wilkinson, D. (2015). Educational reforms and development in Japan: language and culture education for global competitiveness. International Journal of Higher Education Management, 17(4), 555-566. 